Tim Faasen ${ }^{*}$

\title{
Inpabasis intermedia, a new species of damselfly from Peru (Odonata: Coenagrionidae); with an illustrated key to all known Inpabasis-species
}

\author{
https://doi.org/10.23797/2159-6719_24_7
}

Received: 30 August 2020 - Accepted: 20 December 2020 - Published: 8 July 2021

\begin{abstract}
Inpabasis intermedia sp. n. (holotype ${ }^{\top}$ : Peru, Loreto Región) is described and illustrated. An illustrated key to both sexes is given for all members of the genus. Males of I. intermedia can be distinguished from its congeners by the angled division laterally between dark and light areas of the pterothorax, by the short unbranched paraprocts and rounded cerci which bear only a small apical tooth and by the genital ligula with two long apical processes ending in a flattened hook. Females can be distinguished by the dorsoposteriorly directed posterior prothoracic lobe with straight hind margin.

http://www.zoobank.org/urn:lsid:zoobank.org:pub:18F2C9D3-28BC-4329-A001-657860A858AB
\end{abstract}

Keywords: dragonfly, South America

\section{Introduction}

Inpabasis is a small genus confined to the Amazon basin with records known from French Guiana, Surinam, Guyana, Venezuela, Brazil, Peru and Colombia. It was originally erected by Santos in 1961 to receive the following new species: I. hubelli Santos, 1961, I. machadoi Santos, 1961 and I. eliasi Santos, 1961 (type species). He noted the similarity between Leptobasis rosea described by Selys in 1877 and his species of Inpabasis, but did not include it in the new genus as Selys didn't mention the presence of a supra-anal plate on S10. Garrison and Costa (2002) recognized I. eliasi as a junior synonym of $L$. rosea resulting in the recombination Inpabasis rosea.

Thirteen years later a new species, I. nigridorsum Bota-Sierra \& Faasen, 2015, was described based on material from the Amazonian parts of Peru and Colombia. In this paper I. intermedia sp. $\mathrm{n}$. is described from northeastern Peru, bringing the total number of Inpabasis species to five. Furthermore, a key is presented to males and females of all known species of Inpabasis.

\section{Materials and methods}

Specimens of the new species were collected during a collecting trip in the Loreto Región in northeastern Peru in 2009. They were netted, preserved using acetone, dried and stored in parchment bags and identified using Santos (1961), Garrison \& Costa (2002), Garrison et al. (2010) and Bota-Sierra et al. (2015). The holotype was deposited in the Museo de Historia Natural, Universidad Nacional Mayor de San Marcos, Lima; paratypes are housed in the National Museum of Natural History Naturalis, Leiden, the Netherlands. After identification the specimens were compared with specimens of related species collected in the same area in 2009-2015 (personal collection of the author, including $7 \hat{\partial}$ and 6 I I. hubelli and $4 \hat{\partial}$ I. nigridorsum) and specimens loaned by Dr. Rosser W. Garrison (3 $\widehat{\delta}$ and 2 + I. machadoi collected by F.M. Oliveira), Dra. Diana Silva Dávila (MUSM; 1 $\widehat{\partial}$ I. intermedia and 1 I I. nigridorsum, collected by the author) and Max Caspers (RMNH; $5 \hat{\sigma}$ and 1 of I. rosea collected by D.C. Geijskes and J. Belle).

The illustrations of preserved specimens were made with the aid of focus stacking photography (Canon EOS 90D body with a Canon MP-E 65mm lens and a Nikon CF-N 10x microscopic lens mounted on a Cognisys StackShot Macro Rail). 
Body morphology nomenclature follows Garrison et al. (2010). Measurements are in millimetres; abdominal length excludes appendages. Abbreviations used are as follows: $\mathrm{FW}=$ fore wing; $\mathrm{HW}=$ hind wing; $\mathrm{CuP}=$ Cubitus posterior; $\mathrm{RP} 2=$ Radius posterior, second branch; $\mathrm{S} 1-10=$ abdominal segments 1 to 10; MUSM = Museo de Historia Natural, Universidad Nacional Mayor de San Marcos, Lima, Peru; RMNH = National Museum of Natural History Naturalis, Leiden, the Netherlands.

\section{Inpabasis intermedia sp. nov.}

\section{Etymology}

The species is named intermedia (adjective), Latin for 'between' or 'in the middle', referring to its abdomen, which is dorsally black for approximately $40 \%$, thus between I. nigridorsum (more than half black dorsally) and I. rosea, I. hubelli and I. machadoi (predominantly red dorsally).

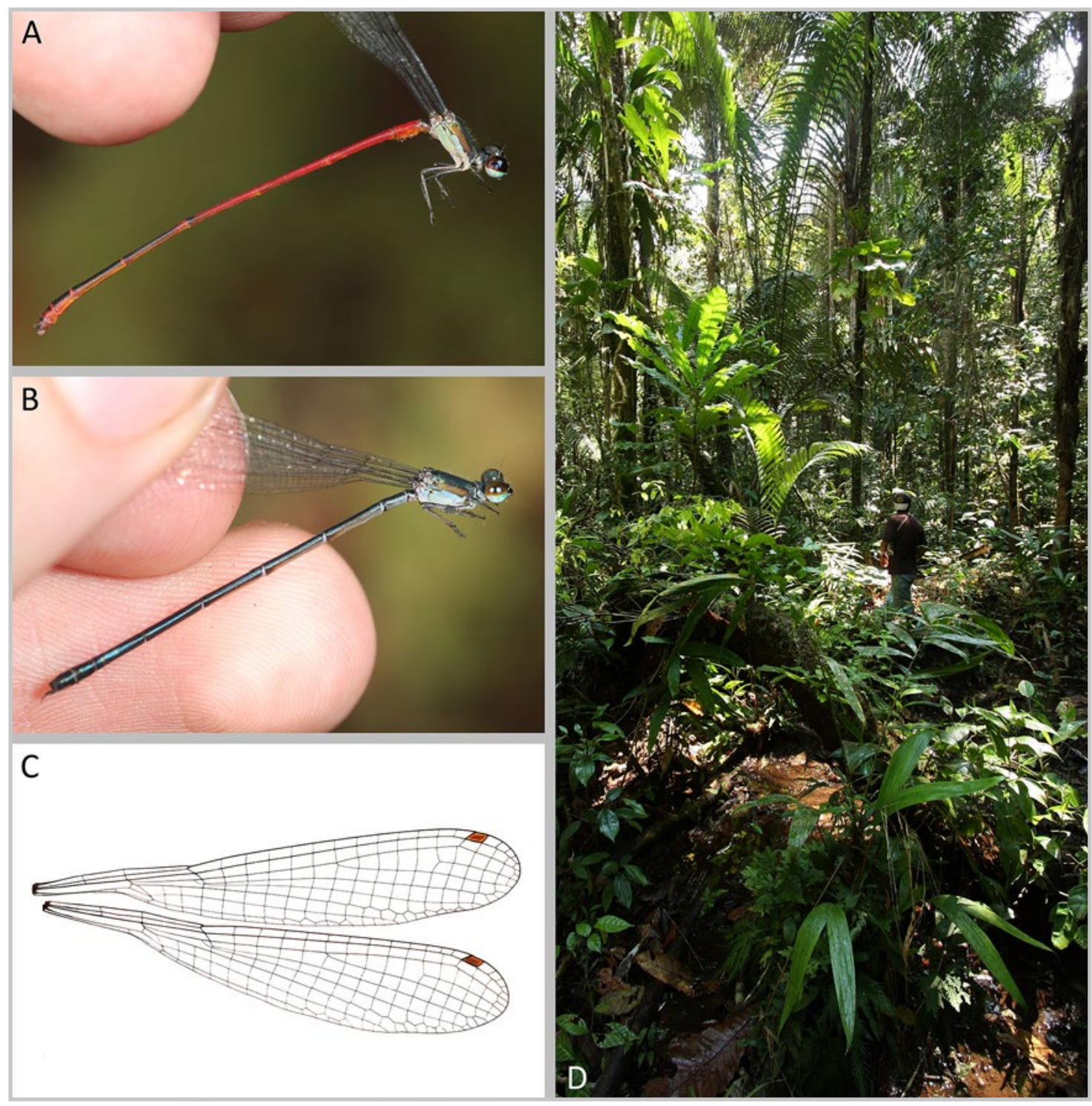

Figure 1. Inpabasis intermedia: A. habitus male paratype; B. habitus female paratype; C. wing male holotype; D. habitat. 


\section{Type specimens}

Holotype $\widehat{\lambda}$ : Peru, Loreto Región, just north of Tamshiyacu-Tahuayo Reserve, near Río Blanco in terra firme forest, elevation $120 \mathrm{~m}, 4.372778^{\circ} \mathrm{S}, 73.18583^{\circ} \mathrm{W}$ (06 viii 2009), leg. T. Faasen [MUSM].

Paratypes: $1 \hat{\jmath}$ and $1 q$ in copula, same data as holotype, leg. T. Faasen [RMNH].

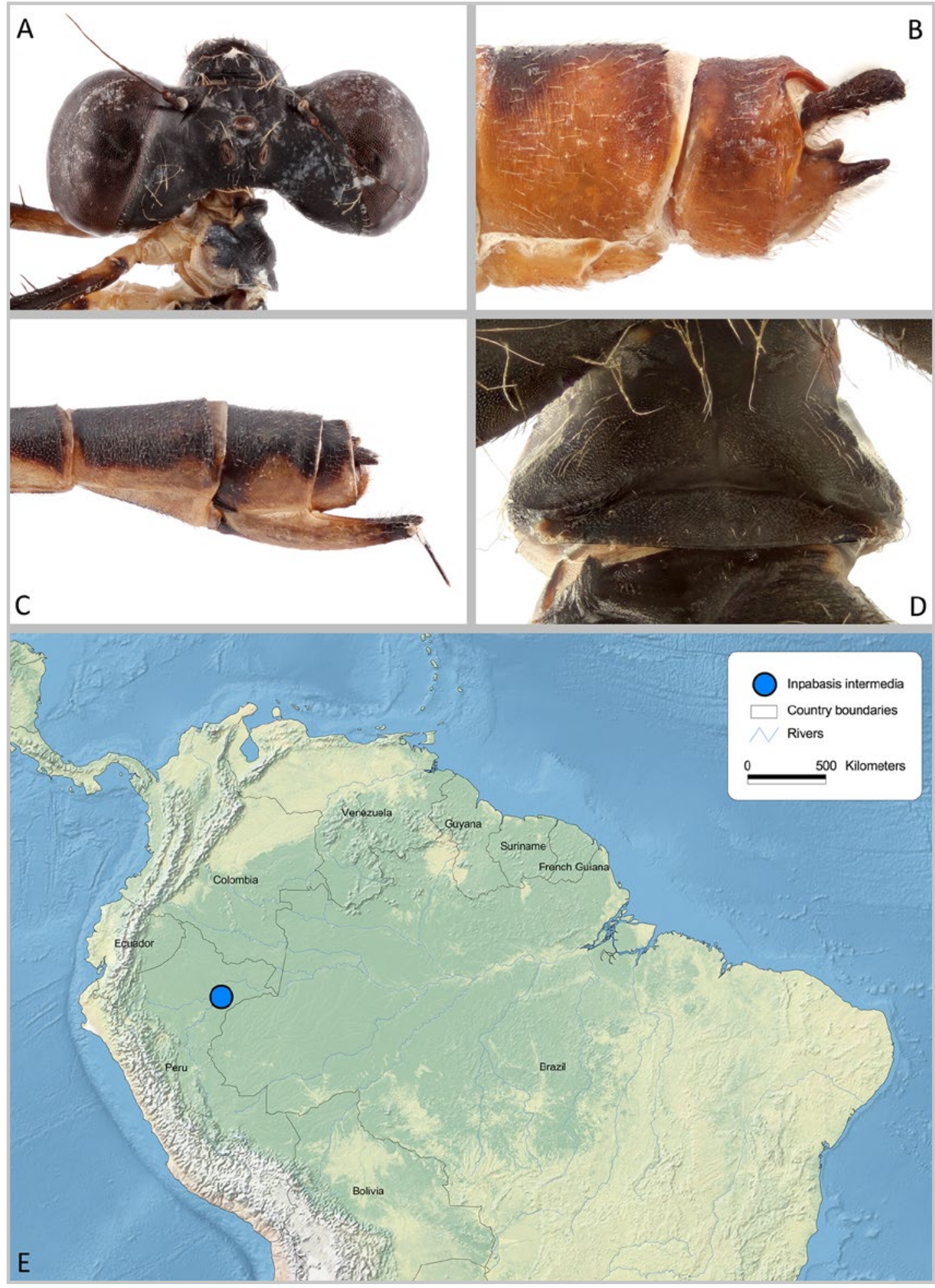

Figure 2. Inpabasis intermedia: A. head male paratype dorsal view; B. cerci and paraprocts male paratype lateral view; C. ovipositor female paratype lateral view; D. prothorax male holotype dorsal view; E. distribution map. 


\section{Description of male holotype}

Head: Black except for the following small pale areas: narrow apical margin of labrum, small ventrobasal spot on mandibles, ventral half of genae, small triangular spot on either side of frons bordering eye rim and tiny spot on either side of ocelli. Black areas mostly dull due to reticulation; area between frons and eye margin shiny. Frons angled. Postocular lobes not protruding posteriorly beyond level of hind margin of compound eyes. Eyes of preserved specimen brown (as in Figure 2A).

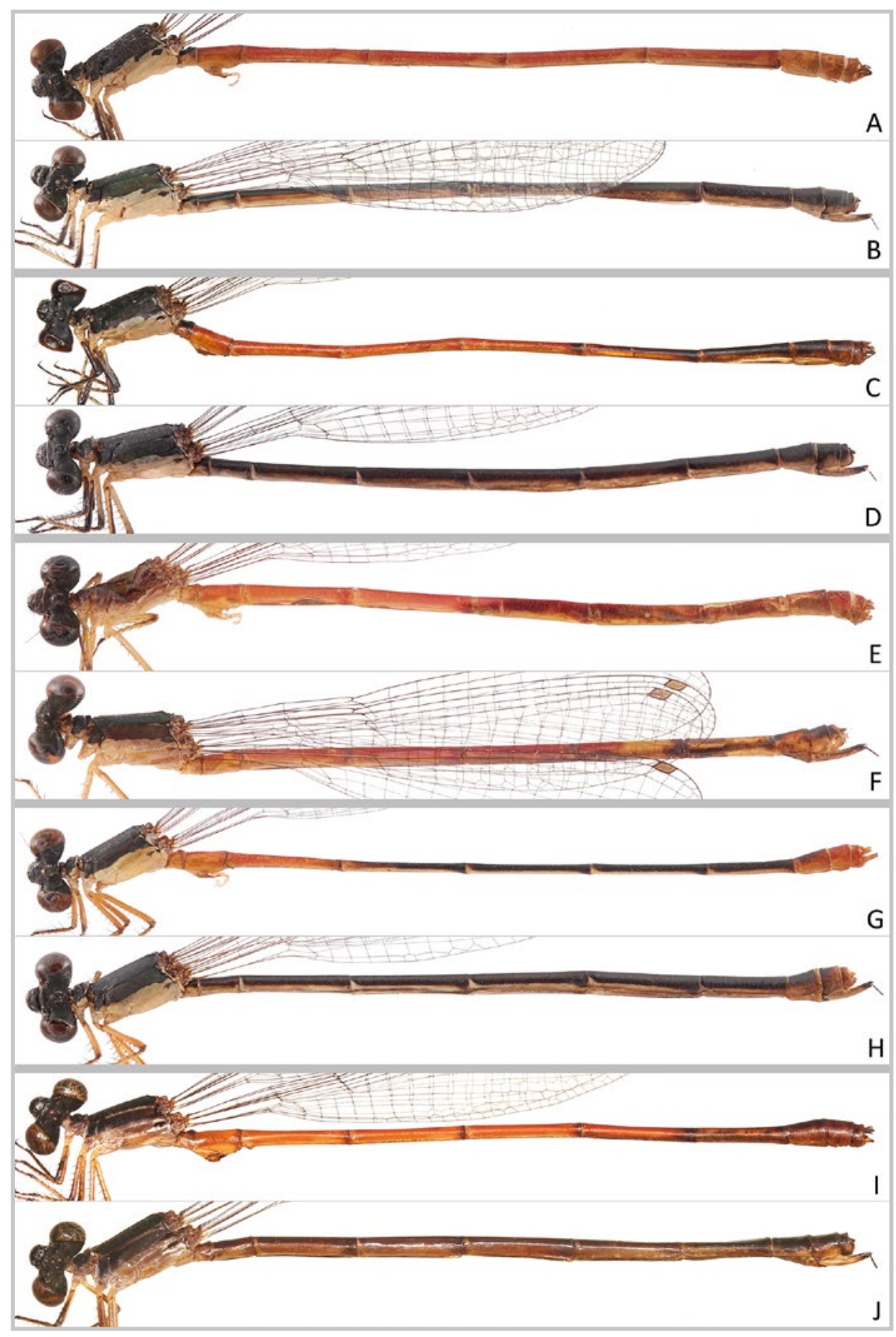

Figure 3. Habitus: Inpabasis hubelli Santos, 1961 A. male, B. female; Inpabasis intermedia C. male (holotype), D. female (paratype); Inpabasis machadoi Santos, 1961 E. male, F. female; Inpabasis nigridorsum Bota-Sierra \& Faasen, 2015 G. male (paratype), H. female (paratype); Inpabasis rosea (Selys), 1877 I. male, J. female. 


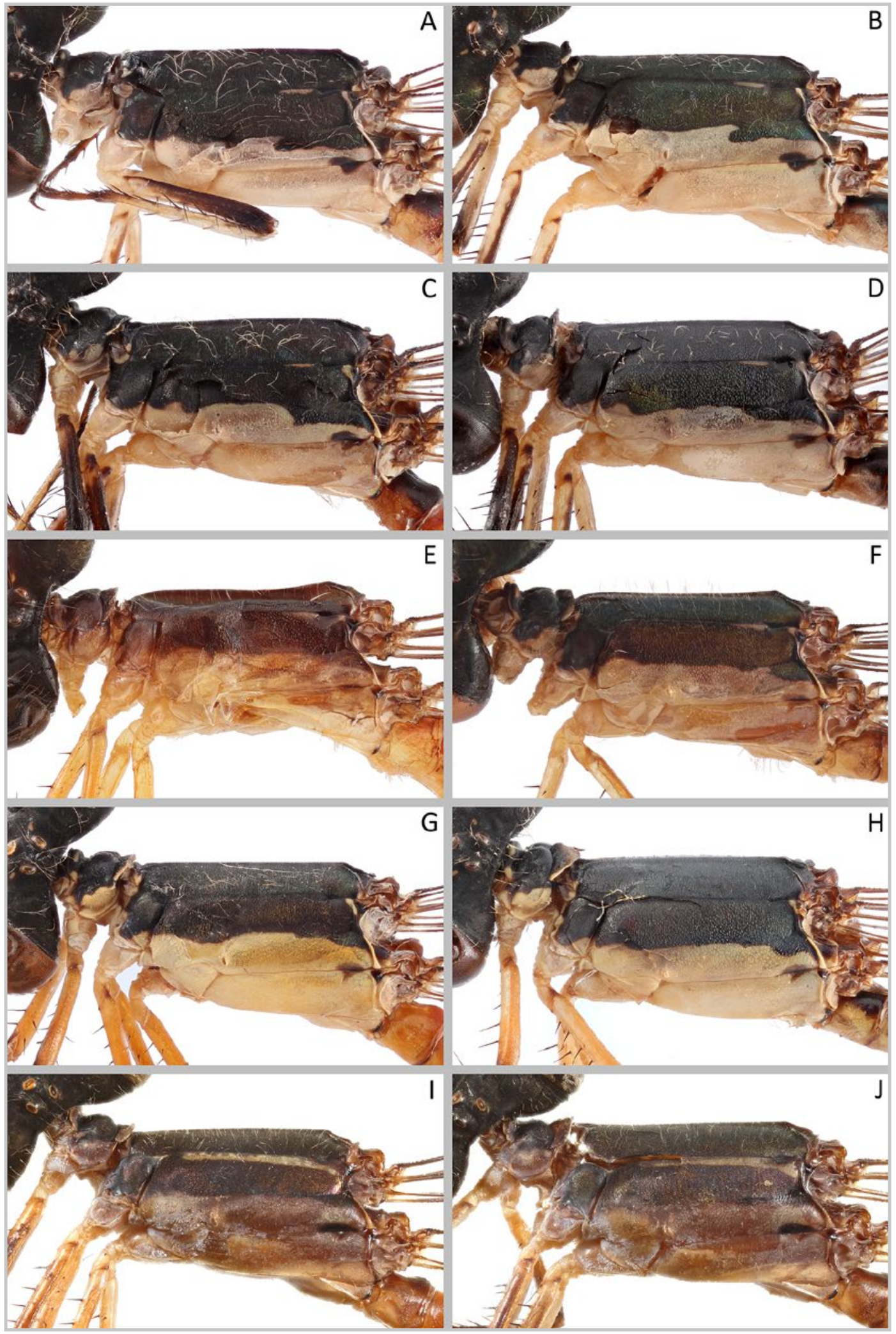

Figure 4. Prothorax and pterothorax: Inpabasis hubelli Santos, 1961 A. male, B. female; Inpabasis intermedia C. male (holotype), D. female (paratype); Inpabasis machadoi Santos, 1961 E. male, F. female; Inpabasis nigridorsum Bota-Sierra \& Faasen, 2015 G. male (paratype), H. female (paratype); Inpabasis rosea (Selys), 1877 I. male, J. female. 
Thorax: Prothorax black with apical portions of pleura, and posterolateral angles of posterior lobe pale. Posterior prothoracic lobe narrow with smooth, convex posterior margin; directed horizontally in same plane as dorsal surface of thorax (Figure 2D and 4C). Pterothorax pale yellowish ventrally, including coxa, metepimeron and most of metepisternum. Mesepisternum and mesepimeron entirely black with slight metallic iridescence. Mesinfraepisternum iridescent black, except for pale ventral margin. Metepisternum with sharply defined subrectangular iridescent black area near posterior margin, covering $40 \%$ of its length. Dark brown semi-circular spot on posterior end of suture between metepisternum and metepimeron and narrow $0.4 \mathrm{~mm}$ long pale stripe on mesopleural suture $0.4 \mathrm{~mm}$ from posterior end. Mesostigmal plates iridescent black with pale tip (Figure 4C).

Legs: femora brown, almost black distally; inner surface of tibia and distal end brown, tarsi brown, almost black apically, claws brown, spurs dark brown. Base of femora and outer surface of tibiae pale.

Wings hyaline. Pterostigma covering one cell, light brown; $\mathrm{CuP}$ at end of petiolation at about 3/4 of length between antenodals 1 and 2 in both FW and HW. Postnodals: 12 in both FW and HW. RP2 branching at postnodal 6 in FW, at postnodal 5 in HW (see Figure 1C).

Abdomen: Red, with dark dorsal markings on S1, on posterior $10 \%$ of S5, on posterior $80 \%$ of S6, on S7-8 and on anterior half of S9 (see Figure 3C). S10 dark reddish dorsally; posterodorsal margin with decumbent, bifid process with pointed, divergent apices (Figure 5B).

Cerci almost parallel sided, slightly spoon shaped; tip broadly rounded with medial surface densely haired; apical tooth small, directing medially (Figure 5B). Paraprocts conical; tips slightly curved medially; red basally, darkened apically; slightly shorter than cerci. Genital ligula with well-developed terminal fold; at base of flexure a pair of chitinized structures each forming a row of 4 (right) or 5 (left) closely aligned stiff setae; apex of ligula bifurcated with two tips in the form of a flattened hook, in lateral view with a small triangular lobe proximal to apical hook; flagellae absent (Figure 6B).

Dimensions: Total length $34 \mathrm{~mm}$. Abdomen length $28 \mathrm{~mm}$. FW length $19.5 \mathrm{~mm}$. HW length $19 \mathrm{~mm}$.

\section{Description of female paratype}

Head: Color pattern as in holotype, but with additional pair of short light lines on margin between postclypeus and antefrons.

Thorax: As in holotype, but posterior prothoracic lobe directed upwards at a $50^{\circ}$ angle above dorsal surface of pterothorax, hind margin \pm straight (Figure 4D). Iridescent black area on metepisternum near posterior margin with anteroventral corner rounded (Figure 4D). Legs: femora black on extensor surface, mostly pale on flexor surface, distally all black. Wings: $\mathrm{CuP}$ at end of petiolation at about 2/3 of length between antenodals 1 and 2 in both FW and HW. Postnodals: 11 in right HW. RP2 branching proximal to postnodal 7 in right $\mathrm{FW}$.

Abdomen: S1-10 completely dark dorsally with metallic iridescence (Figure 3D). Cerci dark. Paraprocts light. Ovipositor light with dark tip extending $0.5 \mathrm{~mm}$ past cerci. Stylus on tip of ovipositor 0.6 mm long, dark. Vulvar spine absent (Figure 2C).

Dimensions: Total length $32 \mathrm{~mm}$. Abdomen length $26 \mathrm{~mm}$. FW length $20.5 \mathrm{~mm}$. HW length $19.5 \mathrm{~mm}$.

\section{Variation in male paratype}

Head: As in holotype, but with additional pair of short light oblique lines on margin between postclypeus and antefrons (Figure 2A).

Thorax: As in holotype, but $\mathrm{CuP}$ at 2/3 of length between antenodals 1 and 2 in FW. Postnodals: 11 in HW and right FW. RP2 branching proximal to postnodal 7 in right FW, at postnodal 6 in both HW.

Abdomen: As in holotype, but paraprocts with basal plate slightly more pronounced mediodorsally, with paraprocts in spread position from lateral view this seems almost tooth like (Figure 2B).

Dimensions: As in holotype, but total length $36 \mathrm{~mm}$ and abdomen length $29.5 \mathrm{~mm}$. 


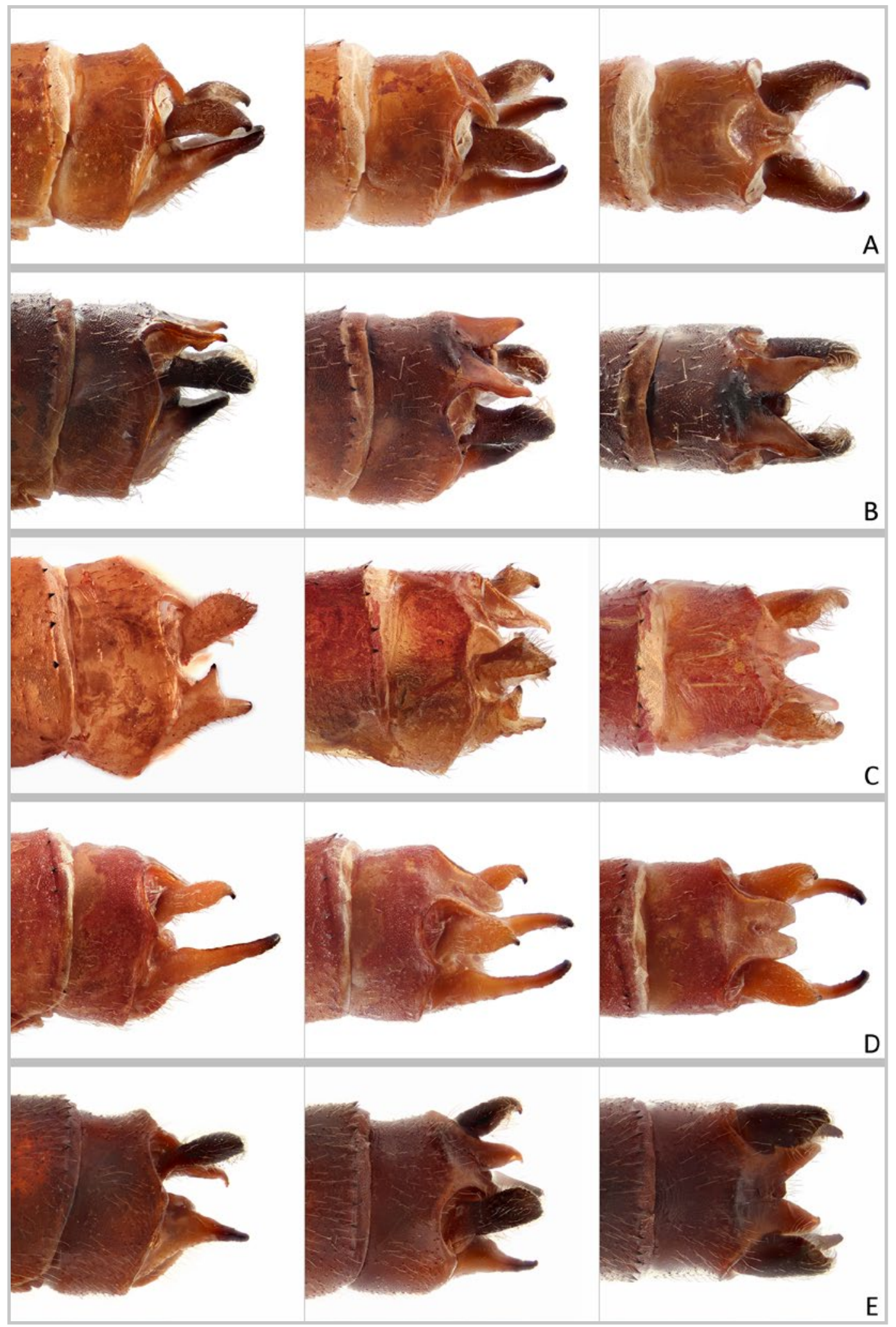

Figure 5. Cerci and paraprocts, lateral, mediodorsal and dorsal view: A. Inpabasis hubelli Santos, 1961; B. Inpabasis intermedia (holotype); C. Inpabasis machadoi Santos, 1961; D. Inpabasis nigridorsum Bota-Sierra \& Faasen, 2015 (paratype); E. Inpabasis rosea (Selys), 1877. 


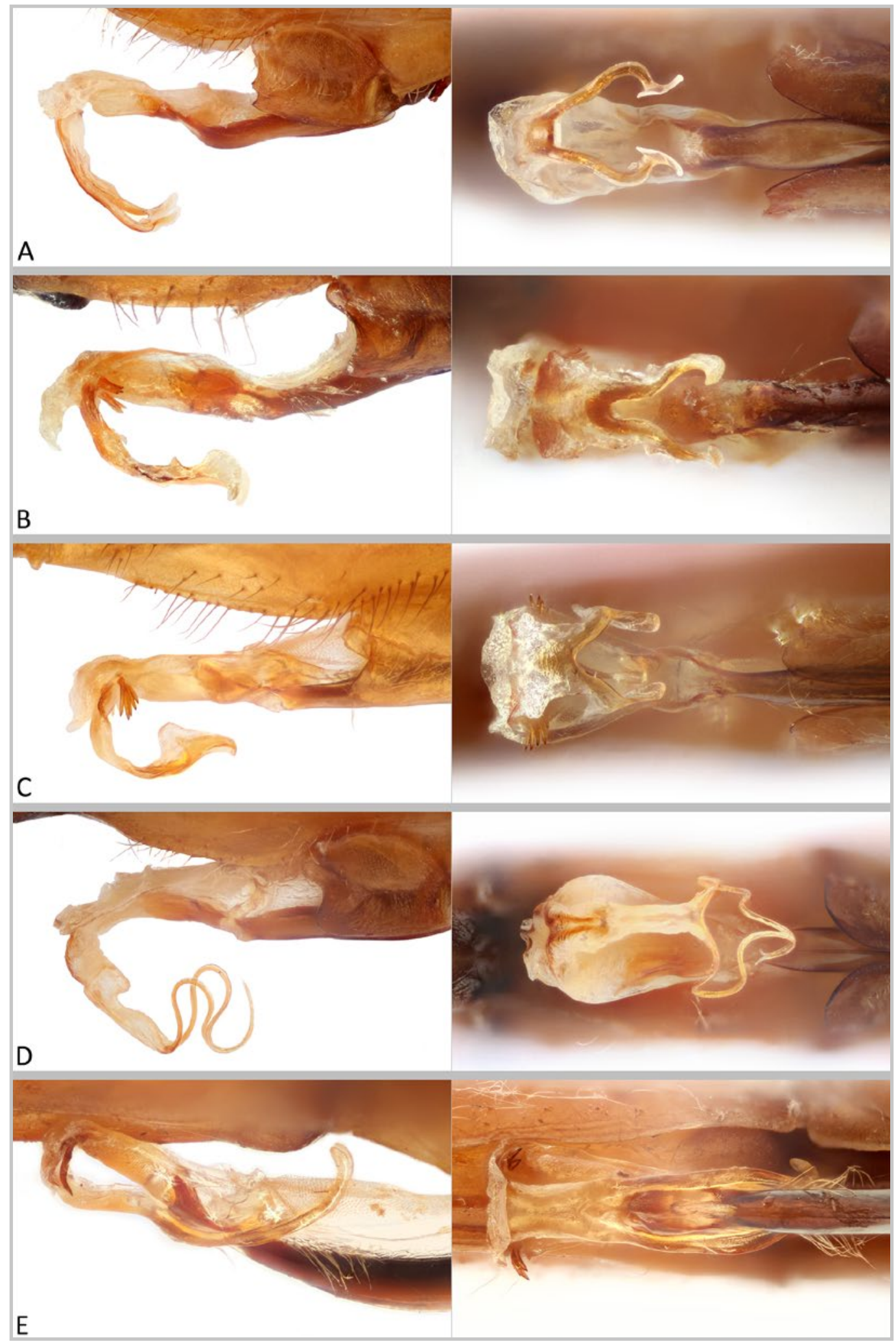

Figure 6. Genital ligula, lateral and ventral view: A. Inpabasis hubelli Santos, 1961; B. Inpabasis intermedia (holotype); C. Inpabasis machadoi Santos, 1961; D. Inpabasis nigridorsum Bota-Sierra \& Faasen, 2015 (paratype); E. Inpabasis rosea (Selys), 1877. 


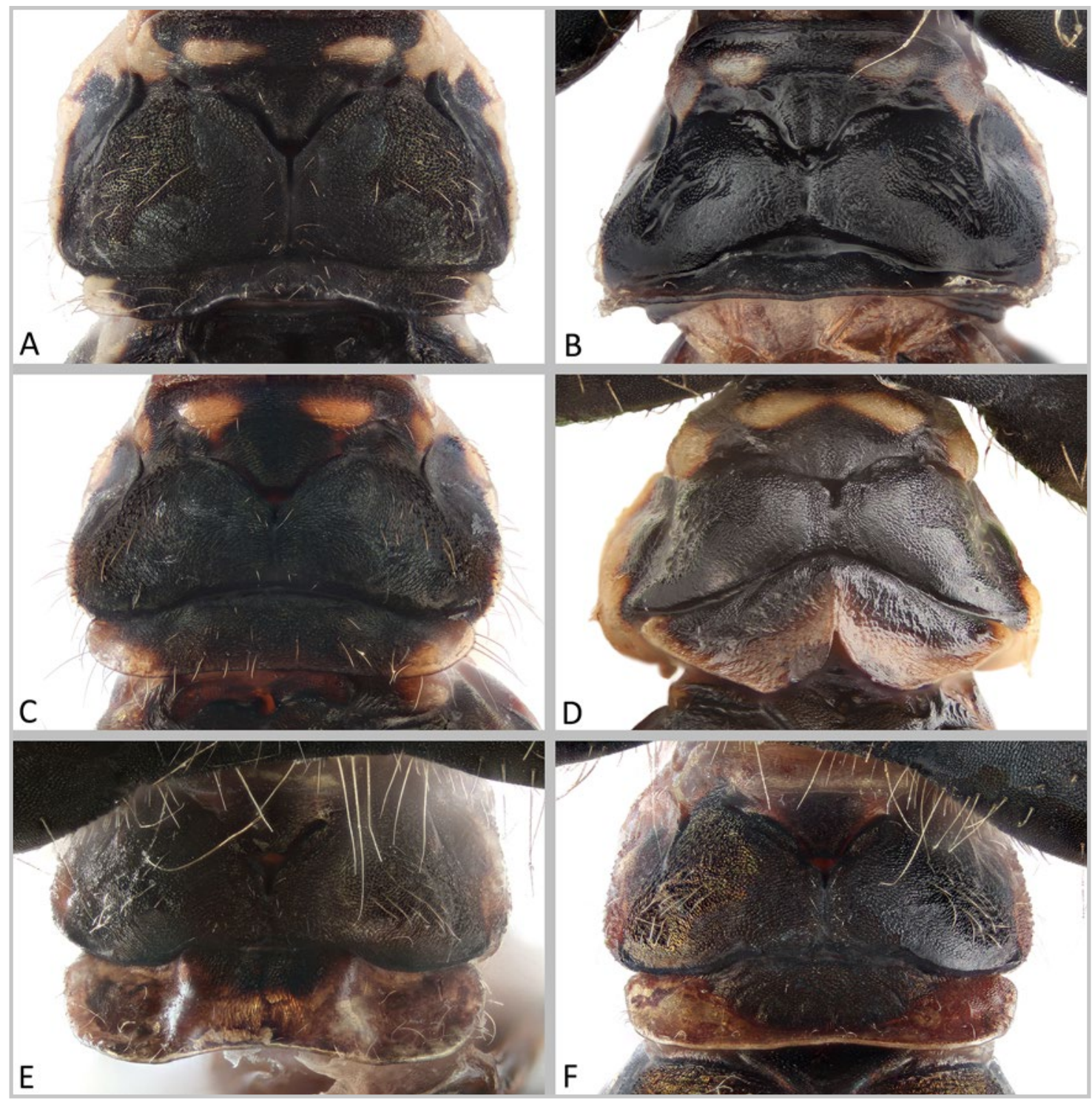

Figure 7. Prothorax, dorsal view: A. Inpabasis hubelli Santos, 1961 female; B. Inpabasis intermedia female (paratype); C. Inpabasis machadoi Santos, 1961 female; D. Inpabasis nigridorsum Bota-Sierra \& Faasen, 2015 female (paratype); E. Inpabasis rosea (Selys), 1877 female; F. Inpabasis rosea (Selys), 1877 male.

\section{Remarks}

Both male and female paratype were photographed when alive (Figures 1A and B), providing color information. Reddish parts of abdomen in male bright red. In both male and female: eyes light blue on ventral half and dark brown dorsally; dorsal half of metepisternum anterior to iridescent black area light blue; ventral half yellow-green. Other light parts yellowish in male and greyish light blue in female. 


\section{Diagnosis}

Males of Inpabasis intermedia can be distinguished from all other congeners by the angled division laterally between dark and light areas of the pterothorax (Figure 4C), by the short unbranched paraprocts and rounded cerci with only a small apical tooth (Figure 5B) and by the genital ligula with two long apical processes ending in a flattened hook (Figure 6B). Other species of Inpabasis have the division between dark and light areas in a linear fashion (Figures 4E and 4I), shallowly undulating (Figure 4G) or deeply s-shaped (Figure 4A). Their paraprocts are either longer (Figures 5A, 5D and 5E) or bear a large dorsal tooth (Figure 5C). Their cerci are less rounded apically and bear a larger apical tooth (Figures 5A, 5C, 5D and 5E). The apical processes of their genital ligula are either shorter (Figure 6C) or not shaped as a flattened hook (Figure 6A, 6D and 6E).

Additional characteristics that can be used to separate males of $I$. intermedia from specific congeners: the narrow posterior prothoracic lobe (Figure 2D) (wider in I. rosea, Figure 7F), reduced humeral stripe (Figure 4C) (entire in I. rosea, Figure 4I), long terminal fold of the genital ligula (Figure 6B) (short in I. hubelli and I. nigridorsum, Figures 6A and 6D; indistinct in I. rosea, Figure 6E) and the paired cluster of long chitinized stiff setae at the flexure of the genital ligula (Figure 6B) (absent in I. hubelli and I. nigridorsum, Figures 6A and 6D).

Females of Inpabasis intermedia can be distinguished from all other congeners by the dorsoposteriorly oriented posterior lobe of the prothorax with \pm straight hind margin (Figures $4 \mathrm{D}$ and $7 \mathrm{~B}$ ). Other species have either a hind margin that is concave in dorsal view (Figure 7A) or the posterior lobe is directed posteriorly (Figures 4F, 4H and 4J).

Additional characteristics that can be used to separate females of I. intermedia from specific congeners: the undulated division laterally between dark and light areas of the pterothorax (deeply sshaped I. hubelli (Figure 4B); the reduced humeral stripe (Figure 4D) (entire in I. rosea, Figure 4J) and the entire hind margin of the posterior prothoracic lobe (Figure 7B) (with a deep median incision in I. nigridorsum, Figure 7D).

\section{Key to species of Inpabasis}

The main text of the key presents structural characteristics and (in the key to males) known distribution. Smaller indented texts provide additional information, including size and color characteristics and although the latter are considered less stable than structural characteristics they can be useful as a control option or as a workaround when studying specimens in the field or specimens that are damaged.

\section{Key to males}

1. Pterothorax with narrow pale stripe along almost entire length of humeral suture (Figure 4I); posterior lobe of prothorax relatively large (Figure 7F); paraprocts unbranched, as long as or slightly surpassing cerci; genital ligula ending in two long, slightly upcurved, inornate, blunt, tube-like processes; terminal fold indistinct (Figure 6E). Central and eastern Amazonia (Venezuela, Guyana, Suriname, French Gui-

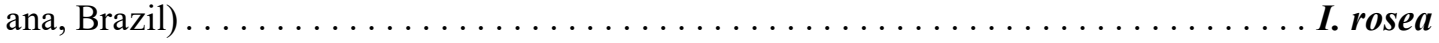

Relatively large species (usually $>37 \mathrm{~mm}$ ). Abdomen mostly red, but might show some darkening where segments join and dorsally on apical segments; paired cluster of long chitinized stiff setae at flexure of genital ligula present. 
1'. Pterothorax with light humeral stripe reduced to a small posterior spot (Figure 4A) or absent (Figure 4G); posterior lobe of prothorax narrower, at least laterally (Figure 2D); paraprocts longer or shorter than cerci or with a prominent dorsal tooth; genital ligula flattened apically or with a thin, strongly undulating flagella; terminal fold clearly visible. Central or western Amazonia $\ldots \ldots \ldots \ldots \ldots \ldots \ldots \ldots$

On average smaller species (usually 30-36 mm).

2. (1) Paraprocts clearly surpassing cerci (by $\pm 1 / 2$ the length of cerci; Figure 5D); genital ligula ending in two long, strongly undulating flagellae (Figure 6D). Western

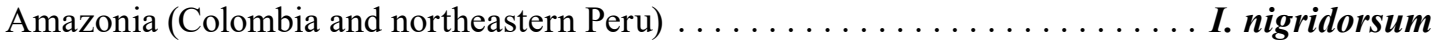

Abdomen usually S4-7(-8) dorsally predominantly dark; apical segments red (Figure $3 G$ ); terminal fold on genital ligula short; clusters of long chitinized stiff setae at flexure of genital ligula absent; femora usually light, including extensor surface.

2'. Paraprocts shorter, at most slightly surpassing cerci; genital ligula bifurcated with enlarged, flattened tip, without flagella. Central or western Amazonia . . . . . . . . 3

Abdomen usually not predominantly dark on middle segments: abdomen mostly red or apical segments dark.

3. (2) Paraprocts with large triangular dorsal tooth at \pm same distance from tip as its own height (Figure 5C); apical processes of bifurcated genital ligula relatively short with strongly enlarged apex comprising $>1 / 2$ of length of processes (Figure 6C). Central Amazonia (Venezuela, Brazil). .

I. machadoi

Division laterally between dark and light areas of pterothorax straight or shallowly undulating

(Figure 4E); femora usually light, including extensor surface; abdomen usually entirely red; paired cluster of long chitinized stiff setae at flexure of genital ligula present.

3'. Paraprocts without large dorsal tooth (but sometimes basal plate protruding somewhat tooth-like dorsomedially: Figure 2B); apical processes of bifurcated genital ligula longer with enlarged apex smaller (comprising $<1 / 2$ of length of processes). Western Amazonia (northeastern Peru) . . . . . . . . . . . . . . . .4

Division laterally between dark and light areas of pterothorax clearly not straight, deviating from interpleural suture in an angle (Figure 4C) or s-shaped (Figure 4A) at 2/3 of its length; femora usually darkened, at least on extensor surface.

4. (3) Cerci with prominent apical tooth curving ventrally; paraprocts extending apically as far as cerci or slightly beyond (Figure 5A); paired clusters of chitinized stiff setae at flexure of genital ligula absent; tip of apical processes of bifurcated genital ligula T-shaped (Figure 6A)

I. hubelli

Division laterally between dark and light areas of pterothorax s-shaped (Figure 4A); paired

posterodorsal processes on S10 curving between cerci usually tongue-shaped, parallel and contiguous* (Figure 5A).

4'. Cerci apically rounded with small apical tooth directing medially, obscured by long hairs; paraprocts shorter than cerci (Figure 5B); paired clusters of chitinized stiff setae at flexure of genital ligula present; tip of genital ligula shaped like a broadly flattened, caudally projecting hook (Figure 6B)

\section{I. intermedia}

Division laterally between dark and light areas of pterothorax angled (Figure 4C); paired posterior processes on S10 usually with triangular tip, diverging apically** (Figure 5B).

\footnotetext{
** It is uncertain how stable the shape of the paired posterodorsal processes on $\mathbf{S 1 0}$ is in I. intermedia and I. hubelli. There is apparently variability in I. nigridorsum: the Colombian holotype has pointed, diverging processes whereas the Peruvian paratypes have tongue-shaped parallel ones (Bota-Sierra et al., 2015).
} 


\section{Key to females}

1. Pterothorax with narrow light humeral stripe along \pm entire length of humeral suture (Figure 4J); posterior lobe of prothorax large, directing posteriorly, with a slightly elevated median 1/3 flanked by two depressed lateral sides, hind margin entire (Figure $7 \mathrm{~F}$ )

Relatively large species (usually $>37 \mathrm{~mm}$ ).

1'. Pterothorax with light humeral stripe reduced to a small posterior spot (Figure 4F) or absent (Figure $4 \mathrm{H}$ ); posterior lobe of prothorax narrower or hind margin with median incision. . . . . . . . . . . . . . . . . . . . . . . . .

Smaller species (total length usually $30-36 \mathrm{~mm}$ ).

2. (1)Posterior lobe of prothorax directed posteriorly, at same level as dorsal plane of pterothorax and prothorax (Figures $4 \mathrm{~F}$ and $4 \mathrm{H}) \ldots \ldots \ldots \ldots \ldots \ldots \ldots \ldots \ldots \ldots$

Usually at least S10 and appendages entirely light (reddish); femora usually light including extensor surface.

2'. Posterior lobe of prothorax elevated, directed dorsoposteriorly above dorsal plane of pterothorax and prothorax (Figures 4B and 4D) ..................

S1-10 dorsally and cerci usually dark; femora partly darkened, at least on extensor surface.

3. (2) Posterior lobe of prothorax enlarged, with a deep median incision (Figure 7D) ... I. nigridorsum Abdomen usually predominantly dark dorsally (Figure $3 H$ ).

3'. Posterior lobe of prothorax narrower with entire hind margin (Figure 7C) I. machadoi Abdomen usually predominantly red (Figure $3 F$ ).***

4. (2) Posterior lobe of prothorax with lateral sides less erect than medial part, resulting in a hind margin that is concave in dorsal view (Figure $7 \mathrm{~A}$ ) ................
Division laterally between dark and light areas of pterothorax s-shaped at $2 / 3$ of it length (Figure 4B).

4'. Posterior lobe of prothorax with lateral sides projecting upwards as steep as medial part, resulting in a \pm straight hind margin (Figure $7 \mathrm{~B}$ ) ................ intermedia Division laterally between dark and light areas of pterothorax angulate or undulate, not s-shaped (Figure 4D).

\section{Habitat and ecology}

All specimens of Inpabasis intermedia were collected from a wet depression within terra firme rain forest in the Amazon basin (Figure 1D). Standing surface water was present, but very shallow. There was only a thin organic soil top layer, indicating rapid decomposition of organic matter. Palms were present but not completely dominating (as they are in aguajal; Myster, 2009). Since a pair in copula was collected it seems likely that they reproduced locally. Their behavior resembled other species of the genera: they spent most of their time perching on plants in the understory of the forest (Garrison et al., 2010).

\footnotetext{
*** Bota-Sierra et al., 2015 state that females of all known species have a predominantly black abdomen dorsally. This is mostly correct, but $I$. machadoi is an exception.
} 
The following species were seen at the type locality: Argia indicatrix Calvert, 1902, Argia infumata Selys, 1865, Argia kokama Calvert, 1909, Amazoneura ephippigera (Selys, 1886), Inpabasis nigridorsum Bota-Sierra \& Faasen, 2015, Pseudotepuibasis garrisoni Stand and Pérez, 2020, Heteragrion breweri De Marmels, 1989, Argyrothemis argentea Ris, 1911 and Uracis infumata (Rambur, 1842). As the wet depression was only small some of the species mentioned here might have wandered in from adjacent habitats.

All three specimens of I. intermedia were collected in August (halfway into the dry season). The flight period might be much longer, but no sampling data from other parts of the year is available. Inpabasis nigridorsum (a species primarily found in palm swamps) flies both in the wet and the dry season, but palm swamps often have relatively stable water levels compared to the shallow depression where I. intermedia was found. Seasonal dehydration might give rise to a deviating flight period.

\section{Distribution}

The species is thus far known only from an Amazonian lowland tropical forest at the northern border of the Tamshiyacu Tahuayo Regional Conservation Area in northeastern Peru (Figure 2E).

\section{Acknowledgements}

I thank Dr. Rosser W. Garrison for confirming several identifications and sending me specimens of I. machadoi, Dra. Diana Silva Dávila (MUSM) for sending me specimens of I. nigridorsum and I. intermedia, Max Caspers (RMNH) for sending me specimens of I. rosea, Dr. Paul Beaver and the staff of Amazonia Expeditions for their support in the fieldwork, Dra. Ana Huamantinco Araujo (UNMSM), Dr. Ing. Vincent Kalkman, Dr. Klaas-Douwe Dijkstra and Dr. Jan van Tol (RMNH) for their support in the planning of the fieldwork, Martha Courbois for her continuous support in every stage of this project both in the Netherlands and in Peru and all three anonymous reviewers for their valuable input for this paper.

Collection of specimens from Tamshiyacu-Tahuayo Reserve was financially supported by the Uyttenboogaart-Eliasen Foundation (the Netherlands; SUB.2014.12.21) and also made possible by the support of the Peruvian government (research permits 164-2009-AGDGFFS-DGEFFS and 0010-2015-SERFOR-DGGSPFFS).

\section{References}

Bota-Sierra, C.A., Moreno-Arias, C. \& Faasen, T. (2015). Preliminary list of Odonata from the Colombian Amazon, with descriptions of Inpabasis nigridorsum sp. nov. \& Diaphlebia richteri sp. nov. (Coenagrionidae \& Gomphidae), International Journal of Odonatology, 18:3, 249-268. http://dx.doi.org/10.1080/13887890.2015.1081637

Garrison, R.W. \& Costa, J.M. (2002). The identity of Agrion? minutissimum Selys, 1876 and Leptobasis rosea Selys, 1877 (Zygoptera: Coenagrionidae). Odonatologica 31(4): 395-401. http://natuurtijdschriften.nl/download?type $=$ document $\&$ docid $=592415$

Garrison, R.W., von Ellenrieder, N. \& Louton, J.A. (2010). Damselfly Genera of the New World; An Illustrated and Annotated Key to the Zygoptera. The Johns Hopkins University Press, Baltimore. https://jhupbooks.press.jhu.edu/content/damselfly-genera-new-world

Myster, R.W. (2009). Plant Communities of Western Amazonia. The Botanical Review 75: 271-291. http://dx.doi.org/10.1007/s12229-009-9032-1

Santos, N. D. (1961). Inpabasis g.n. e trés espécies novas (Coenagriidae: Odonata). Boletim do Museu Paraense Emílio Goeldi (Nova série) Zoología, 34, 1-7. 